\title{
O café em África no período de reconhecimento da independência do Brasil
}

\author{
The coffee in Africa in the period of recognition of the independence of Brazil.
}

\author{
Alan de Carvalho Souza*
}

Como citar esse artigo. Souza, Alan de Carvalho. O café em África no período de reconhecimento da independência do Brasil. Revista Mosaico. 2017 Jul./Dez.; 08 (2): 04-15.

\begin{abstract}
Resumo
Este texto é parte da pesquisa em andamento que investiga a implementação da cultura do café como investimento no povoamento e desenvolvimento de algumas das possessões portuguesas em África (Cabo Verde, São Tomé e Príncipe e Angola) durante a primeira metade do século XIX, a qual pode ser integrada no "projeto imperial português" para África. Assim, apresentaremos os debates parlamentares em torno dos projetos de lei pronunciados a partir das Cortes Extraordinárias com o intuito de promover a diversificação da produção agrícola e o consequente aumento da arrecadação.

Palavras-Chave: Cultura do café; Possessões portuguesas; Debate político.
\end{abstract}

\begin{abstract}
The research analyzes the implementation of the culture of coffee as an investment in the settlement and development of some of the Portuguese colonies in Africa (Cape Verde, São Tomé and Príncipe and Angola) during the first half of the 19th century, which can be integrated in the "Portuguese imperial project" for Africa. Thus, we will present the parliamentary debates around the bills passed by the Extraordinary Cortes with the intention of promoting the diversification of agricultural production and the consequent increase in collection.

Keywords: Coffee culture; Portuguese possessions; Political debate.
\end{abstract}

A partir da iminente emancipação do Brasil, surgiram nas Cortes Extraordinárias as primeiras propostas de se buscar maior desenvolvimento e povoamento nos domínios em África (Cabo Verde, São Tomé e Príncipe e Angola), por meio de uma maior e diversificada produção de gêneros coloniais entre os quais mencionavam o cultivo do café.

Ao analisar os projetos de implantação debatidos pelos deputados, optamos por realizar a investigação confrontando-os com a documentação do Conselho Ultramarino a fim de percebermos a própria discussão e os cenário(s) existente( $\mathrm{s}$ ) nas possessões. Para além desse universo documental, investigamos as representações de comerciantes e particulares enviadas ao Parlamento português e a legislação régia do período.
O cruzamento da documentação apresentou resultados que foram: $1^{\circ} \mathrm{o}$ desconhecimento da produção existente nas possessões; $2^{\circ}$ a implantação do café sem o acompanhamento de medidas "alfandegárias" e $3^{\circ}$ dificuldade para escoar o que era produzido que, por conseguinte, prejudicou a expansão da cultura agrícola durante a década de 1820 .

Uma das questões que afetou à implantação do café foi à manutenção de tarifas diferenciadas para a produção do Brasil após o reconhecimento de sua independência. Esse benefício ocasionou impacto negativo nas possessões por serem submetidas a tarifas superiores as cobradas do antigo membro do Reino. Mediante ao menosprezo pela produção dos domínios em África, foi enviada uma representação para que a situação fosse não só corrigida, como a sua correção fosse utilizada para promover o desenvolvimento de

Afiliação dos autores: Discente do Programa Interuniversitário de Doutoramento em História (PIUDHist). Instituto de Ciências Sociais (ICS) e Centro de História da Faculdade de Letras - Universidade de Lisboa. Bolsista Capes.

*ppunk_alan@hotmail.com 
uma das possessões; nesse caso, Cabo Verde.

Foi num cenário economicamente decadente para duas das três possessões analisadas, Cabo Verde e São Tomé e Príncipe, que as ações de incentivo à diversificação de culturas de gêneros coloniais foram buscadas entre as quais destacamos a cultura do café motivada pela demanda do mercado externo e, principalmente, pelo exemplo brasileiro que em curto espaço temporal, pouco mais de trinta anos, se tornou no maior produtor e fornecedor mundial do grão.

\section{O café a movimentar as margens do Reino}

Em 25 de abril de $1818^{2}$ foi publicado um alvará com o objetivo único de produzir fundos para o melhoramento do estado do Reino por meio do aumento de direitos sobre o comércio destinado ao Brasil. A justificativa utilizada para o aumento das alíquotas sobre determinados produtos foi a redução dos direitos das alfândegas sobre a importação realizada pelo Brasil concedida anteriormente quando da abertura dos portos e pelo Tratado de Comércio e Navegação de 1810. Um dos "produtos" mais atingido com as novas taxas foi o africano escravizado cuja comercialização apresentava forte aumento impulsionado pela sua utilização no cultivo da promissora cultura do café.

Os principais pontos da publicação foram: o aumento para 9.600 réis sobre o desembarque de escravos, pagamento de 600 réis sobre a exportação da arroba de carne salgada e/ou charque via embarcação estrangeira e a redução de $16 \%$ para $15 \%$ do direito de entrada sobre as mercadorias portuguesas.

Para termos a ideia do acréscimo que causaria as novas taxações para a arrecadação nas alfândegas, apresentamos dois números que demonstram o crescimento da importação de africanos. No ano de 1809 foram desembarcado somente porto do Rio de Janeiro 13.171 escravizados, quantitativo que atingiu os $25.080^{3}$ no ano de 1818 . Esse aumento foi influenciado diretamente pela expansão da lavoura de café que naquele momento apresentava aumento substancial na exportação.

Tabela 1. Exportação de café (1817-1821).

\begin{tabular}{ccc}
\hline Autor/fonte & $\begin{array}{c}\text { Quantidades/ } \\
\text { sacas }\end{array}$ & Período \\
\hline Rafael Marquese & $101.666^{*}$ & $1817-1821$ \\
Porto-Alegre & $82.031 * *$ & $1817-1821$ \\
Associação Com. & $103.603 * * *$ & $1817-1821$ \\
\hline do Rio & & \\
\hline
\end{tabular}

Um questionamento que pode ser apresentado é se a nova taxação buscou suprir parte da arrecadação perdida com a proibição de 1815 da comercialização de escravizados ao norte da linha do Equador?

E, nesse contexto de expansão do cultivo cafeeiro no Brasil e aumento da taxa sobre a importação do escravizado, surgiu o café pela primeira vez nas Cortes Extraordinárias em 1821.5 Não enquanto proposta de cultivo nos domínios portugueses, mas envolvido numa disputa entre o Erário, após a apreensão de 65 sacas dos franceses, e uma suposta proprietária, Anna Mallet, que alegava ser a possuidora não só do café, mas de toda a mercadoria apreendida ${ }^{6}$. A contenda que chegou às Cortes foi analisada pela Comissão de Justiça Criminal que optou por remeter o caso ao Governo, visto que seria o assunto de interesse da Fazenda Nacional.

Ainda nas Extraordinárias, após a querela entre o Erário e Ana Mallet, o café passou a ser sistematicamente mencionado e citado nas e pelas propostas que naquele momento buscavam o melhoramento do comércio entre o Brasil e Portugal. A primeira propositura na qual o café "surgiu" teve o objetivo de garantir o fluxo de fornecimento dos gêneros coloniais sem interferência externa, numa clara ação protecionista.

A propositura foi debatida em 15 de março de $1822^{7}$ com o propósito central de beneficiar ambas as margens do Atlântico ${ }^{8}$ com a produção existente. A base era a igualdade e a reciprocidade. Além disso, buscava assegurar o escoamento e o consumo da produção sem nenhum tipo de interferência/concorrência externa. Destaque dado ao art. $7^{\circ}$, por incorporar o café como um dos produtos beneficiados.

Sobaretórica dabusca pelaharmoniadosinteresses de ambas as margens do Atlântico, a preocupação maior era conter o avanço da independência do Brasil, o que não impediu nos debates que sucederam a sugestão de aplicação dos mesmos benefícios para as possessões africanas. Assim, foi sugerido ao art. $7^{\circ}$ a emenda que passaria "de se dizer em lugar de produções do Brazil, se diga: produção das possessões portuguesas".

Alguns meses após esse primeiro debate, já com a iminente separação política do Brasil, os deputados preocupados com a possível ausência de fornecimento dos gêneros brasileiros discutiram em 08 de junho de $1822^{10}$ o projeto de promover o povoamento e a colonização da Ilha cabo-verdiana de São Vicente, mencionando como parte do processo o cultivo das plantas do café e algodão. Entretanto, nesse primeiro momento, a ilha foi apontada pelos deputados como nociva para as mencionadas culturas por ser muito "ventosa" e pouco povoada.

A partir das Cortes Extraordinárias, começou a surgir uma maior preocupação de implantar culturas cujos produtos até então eram produzidos e fornecidos pelo Brasil nas possessões que as vezes cultivava, mas nem sempre a explorava. A princípio, as propostas 
demonstram que o objetivo era uma possível reposição em caso de suspensão do fornecimento causado pela emancipação do Brasil. Para além da questão política, existia a situação na qual se encontravam os domínios portugueses em África. Por exemplo, o estado de miséria de Cabo Verde foi relatado em 1818 que desde os primeiros anos dos Oitocentos sofria com a situação prolongada pela seca e consequente fome. Tão preocupante e delicada foi a questão que gerou a solicitação real de uma investigação sobre as plantas, raízes, frutos medicinais e águas minerais que eram ou poderiam ser produzidas naquele solo. ${ }^{11} \mathrm{Na}$ descrição resultante pôde verificar a citação de uma grande gama de culturas, mas sem menção ao café. ${ }^{12}$

Diante do cenário que se apresentava, mesmo sendo apontada como "ventosa" para o cultivo do café, a Ilha de São Vicente foi objeto da preocupação de se alavancar o desenvolvimento. A cultura do café e do algodão, se implantadas, foi a forma encontrada para iniciar o progresso e assim, a partir da comercialização de seus frutos buscar uma maior diversificação e circulação de produtos agrícolas. No ano seguinte, tendo o mesmo propósito a cultura do café também foi sugerida para a Ilha da Madeira.

A Ilha Terceira, Madeira e os Açores foram objetos da proposta do Deputado Freire de se criar nas mesmas um "batalhão". Durante os debates foi apresentado o projeto do deputado Pimenta de Aguiar que nada tinha em comum com o do deputado Freire e muito menos com a questão do café. Tratava-se da criação de uma Junta de Encanamentos e Estradas na cidade de Funchal. Todavia, ao apresentar a proposta, Pimenta ${ }^{13}$ optou por criticar a opção dos lavradores pela produção do vinho que os ingleses não mais queriam importar e a salientar o clima da Ilha da Madeira, o qual oferecia aos lavradores possibilidades de cultivo de qualquer tipo de planta.

Com a diminuição do mercado para escoar o vinho produzido, mais a ausência de cultura que pudesse substituir o que outrora foi fornecido pela comercialização com os ingleses, a Ilha da "Madeira passou a um estado de penúria". Segundo o deputado Pimenta de Aguiar, essa situação não teria ocorrido se tivesse sido implantada uma cultura agrícola diversificada com a implantação do café e do algodão.

Enquanto cenário de infortúnio começava a atingir a Ilha da Madeira e que já predominava em Cabo Verde; Angola e São Tomé e Príncipe apresentavam perspectivas diferentes.

A ilha de São Tomé apresentou em 1823 a receita de $8.231 \$ 168$ réis..$^{14}$ Desse total, $2.374 \$ 180$ réis eram oriundos da arrecadação de Direitos sobre o Comércio de Escravos. ${ }^{15} \mathrm{O}$ montante representava $28,84 \%$ da receita. Essa arrecadação demonstra a participação da Ilha no tráfico, facto não observado nesse mesmo ano na Ilha de Príncipe. Enquanto constatamos rendimentos sobre o tráfico, não encontramos direitos sobre o café em nenhuma das ilhas, episódio curioso em razão da existência do cultivo do grão na possessão ${ }^{16}$ sugerindonos a análise do mapa da receita e despesa.

Ao investigar o referido documento relativo ao ano de 1823, deparamos com dados alusivos aos direitos dos "Generos emportados em navios Portugueses e Dízimos dos Generos e Mantimentos", nos quais poderiam se encontrar diluídos os recolhimentos sobre o café. Contudo, afirmar tal ocorrência é demasiadamente imprudente em razão do mapa do ano de 1825 fornecer a recolha sobre a comercialização do café denominada "Do Caffé emportado em Navios Nacionaes e Estrangeiros".

Especificamente nos anos de 1823-24 o mapa de receita não apresentou registro da comercialização do café. A ausência, possivelmente, ocorreu em função da negociação realizada por uma embarcação francesa na Ilha de São Tomé sem o devido recolhimento dos direitos. ${ }^{17} \mathrm{O}$ comandante do navio foi acusado de barganhar mercadorias por café sem pagar o valor real dos direitos existentes.

De acordo com o apurado, "pagou simplesmente $162 \$ 000$ réis". A história sobre a questão iniciou-se em julho de 1824 quando o brigue Glaneur carregado de mercadorias aportou em São Tomé e comercializouas com os moradores em troca de café e marfim, especialmente o primeiro.

A querela em torno da negociação ocorreu em razão do valor recolhido pela alfândega de $162 \$ 000$ réis, considerado baixo frente ao volume de café embarcado avaliado em $48 \$ 760$ libras. ${ }^{18}$. Esse episódio demonstra a busca comercial pelo grão que possibilitava o fácil escoamento da produção a justificar a afirmação de ser "procurado anciozamente por todas as naçoens" e de "exportação infalível". ${ }^{19}$

Frente ao baixo valor pago a alfândega, o juiz da mesma determinou o pagamento em "tresdobro" sobre os direitos que deveriam ter sido recolhidos. Segundo as autoridades, o café foi "carregado a sete libras" equivalente a 800 réis. A partir desse valor base foi aplicado o seguinte cálculo: o total de $48 \$ 760$ libras dividido por sete. $O$ resultado obtido foi multiplicado por 800 réis, e desse montante, arredondado para $5.572 \$ 000$ réis. Aplicando a alíquota de $24 \%$, o valor que deveria ter sido recolhido era de $1.337 \$ 280$ réis, o qual sofreu a aplicação da multa de "tresdobro".

Nesse mesmo período em que São Tomé e Príncipe apresentavam questões sobre o não recolhimento de direitos sobre a comercialização do café, Cabo Verde se encontrava em dificuldade e Angola, por sua vez, vivenciava um período de aumento da exportação de escravizados para o Brasil impulsionado exatamente pela lavoura cafeeira. Passamos ao rendimento da Alfândega angolana frente a esse ramo do comércio: 
Tabela 2. Direitos recolhidos sobre a venda de escravizados.

\begin{tabular}{cccc}
\hline & $\mathbf{1 8 2 3}$ & $\mathbf{1 8 2 4}$ & $\mathbf{1 8 2 5}$ \\
\hline Direitos & $89: 536 \$ 050$ & $91: 336 \$ 950$ & $115: 562 \$ 100$ \\
Subsídios & $3: 087 \$ 450$ & $3: 149 \$ 550$ & $3: 984 \$ 900$ \\
Totais & $92: 623 \$ 500$ & $94: 486 \$ 500$ & $119: 547 \$ 000$ \\
\hline
\end{tabular}

Somado ao aumento encontra-se o relato do governador a informar que o comércio interno e externo se encontrava "com a maior actividade, e frequencia, tanto $p^{a}$ o interior, como $p^{a}$ o Brazil, entretanto pela maior parte o emprego destas operacoenz se destina ao tráfico da Escravatura". ${ }^{20}$

A arrecadação gerada pelo tráfico produziu a receita de 306:657\$000 réis com o rendimento total da Alfândega a atingir 480:625\$570 $0^{21}$ réis, ou seja, somente a comercialização de escravizados foi responsável por $63,80 \%$ de toda a arrecadação.

Ao mesmo tempo em que se observa o aumento da arrecadação em Angola; no Brasil verificava-se o crescimento do cultivo e da exportação do café que naquele momento tinha o Rio de Janeiro como principal destino dos escravizados e maior centro produtivo do grão.

\begin{tabular}{cccc} 
Tabela 3. Exportação de café. & & & \\
\hline & $\mathbf{1 8 2 3}$ & $\mathbf{1 8 2 4}$ & $\mathbf{1 8 2 5}$ \\
\hline $\begin{array}{c}\text { Exportação de café } \\
\text { (sacas)* }\end{array}$ & 95.333 & 99.822 & 101.410 \\
$\begin{array}{c}\text { Exportação de café } \\
\text { (sacas)** }\end{array}$ & 226.000 & 274.000 & 224.000 \\
$\begin{array}{c}\text { Importação de escravos } \\
\text { (Rio de Janeiro) }\end{array}$ & 4.278 & 7.137 & 7.993 \\
\hline
\end{tabular}

Com cenário favorável à cultura do café e, por conseguinte, à exportação de africanos, em 6 de dezembro de 1824 foi publicado um Alvará que buscava recíproco "Commercio de Seus Reinos com o de Angola". Ou seja, aumento do comércio de Angola com Portugal que trazia em seu art. $1^{\circ}$ "que por espaço de dez anos (...) todos, e quaesquer generos, que se importarem, ou que se exportarem dos Portos do Reino de Angola e Benguela em directura para os destes Reino de Portugal serão isentos de metades dos direitos $(\ldots){ }^{23}$
Direcionado especificamente para Angola, a publicação buscava estimular a relação comercial da possessão com o resto do Reino; no entanto, o que poderia fornecer Cabo Verde tendo em consideração a situação de miséria em que se encontrava? Mesmo São Tomé e Príncipe que já apresentavam negociação de café, passavam por um período de queda de receita que será demonstrado mais adiante.

Contextualizando, é possível perceber que na prática a redução dos direitos cobrados no comércio entre Angola e Portugal terminou por não provocar o desenvolvimento da agricultura ou uma maior povoação e muito menos, como sugere Gilberto Guizelin, que o referido Alvará buscava a reorientação do comércio marítimo para Portugal. ${ }^{24}$

Primeiro não procurava reorientar o comércio porque nem sequer havia produção suficiente tanto na possessão quanto na metrópole para movimentar a rota. Especificamente em Angola, o domínio do tráfico tornava mais vantajoso, naquele momento, a importação de produtos do que produzi-los. Outrossim, sendo o escravizado o principal produto angolano, o mesmo não podia ser comercializado em Portugal em razão do Alvará régio de 1761.

Quanto à determinação da redução dos direitos, não há nenhuma restrição relacionada à origem inicial dos gêneros, ou seja, não era necessário ser produção exclusiva de Angola e/ou do Reino. Por ter Angola uma relação comercial, em razão do tráfico, mais ativa com o Brasil do que com o próprio Portugal, a determinação contida no Alvará buscava na verdade promover em grande parte o acesso da metrópole aos produtos brasileiros que circulavam na possessão.

Além disso, a publicação de 6 de dezembro de 1824 provocou algo não esperado, o receio pelo fim do tráfico. O alvará gerou esse temor nos negociantes e fabricantes da praça de Lisboa ${ }^{25}$ que cogitaram sobre o objetivo como uma ação frente a "interrupção" do comércio com o Brasil durante o reconhecimento de sua independência fazendo surgir especulações como as “(...) persuasoens do ultimo ministério de Vossa magestade Imperial Real que no termo de quatro annos que vai ter o Commercio da Escravatura pelo tractado com a Inglaterra (...)". ${ }^{26}$

Diante de um cenário de incertezas no comércio, pontuamos sobre o objetivo do alvará versar sobre o favorecimento da circulação da produção brasileira no Reino que em Angola era barganhada na aquisição de escravizados em razão da parca produção angolana e portuguesa.

\section{$O$ reconhecimento da independência e o seu impacto nas possessões}

Em 29 de agosto de 1825 o Brasil obteve o 
reconhecimento português de sua independência por meio do Tratado de Paz e Aliança. Dois pontos desse documento merecem uma maior atenção.

O primeiro é a determinação constante no art. $3^{\circ}$ da não aceitação de proposições de possessões africanas se unirem ao Brasil. O segundo constante no art. $10^{\circ}$ era o restabelecimento imediato das relações comerciais entre Portugal e o Brasil com a taxação de $15 \%$ com os direitos de baldeação e re-exportação da mesma maneira antes aplicados.

O impacto para as possessões em África foi negativo por dificultar não só o ingresso no mercado da metrópole da produção de seus domínios como o próprio desenvolvimento das mesmas.

A manutenção da baixa taxação para os produtos oriundos do Brasil criou dificuldade no desenvolvimento das possessões em África que sofriam a cobrança de $30 \%$ enquanto o ex-integrante do Reino pagava $15 \%$ de direito de entrada em Portugal. Consequentemente, a produção agrícola não se desenvolveu em razão do favorecimento "fiscal" destinado à produção oriunda do Brasil. A fim de comprovar a afirmativa faremos utilização das informações contidas em dois Mapas Estatísticos do ano de 1825, enviados ao Conselho Ultramarino em 25 de novembro de $1826 .{ }^{27}$ Vejamos um a um.

O Mapa do Presídio de Caconda ${ }^{28}$ apresentou a tabela "Diversas produçoenz" contendo: milho; feijão; maçambala; ervilhas e trigo. Já o relativo da Paróquia de São Felippe de Benguela foi possível encontrar: cal; cera; escravos; feijão; farinha; gado; galinhas; marfim; milho; porcos; sal; telha e tijolos com a informação

\begin{tabular}{|c|c|c|c|}
\hline Produtos & Produção & Exportação & $\begin{array}{c}\text { Destino } \\
\text { (Portos de } \\
\text { destinação } \\
\text { da } \\
\text { producão) }\end{array}$ \\
\hline Escravos & 4.610 & 4.408 & $\begin{array}{c}\text { Luanda (179) } \\
\text { Rio de Janeiro } \\
\quad(4.229)\end{array}$ \\
\hline Marfim & 767 & 767 & Luanda \\
\hline Sal & $12.731 *$ & $9.750 *$ & Luanda \\
\hline Telhas & 11.300 & 5.497 & Luanda \\
\hline Tijolos & $24.400 * *$ & 4.935 & Luanda \\
\hline
\end{tabular}

sobre o que foi exportado.

Verifica-se a escassa variedade produzida e o consequente baixo número de produtos destinado à exportação, com a exceção do escravizado abundância

\begin{tabular}{|c|c|c|c|}
\hline Origem & Entrada & & \\
\hline Lisboa & 3 & & \\
\hline Rio de Janeiro & 9 & Destino & Saída \\
\hline Bahia & 2 & Rio de Janeiro & 6 \\
\hline Pernambuco & 1 & Angola & 20 \\
\hline Angola & 12 & & \\
\hline Moçambique & 2 & & \\
\hline
\end{tabular}

era destinado ao Rio de Janeiro.

Ainda sobre os dados de Benguela, apresentamos o quantitativo de entrada e saída de embarcações do ano de 1825 .

Chamamos atenção para os dados de saída. Das 26, apenas seis destinaram-se ao circuito externo. As demais tiveram como destino a própria Angola. Das 12 embarcações brasileiras que entraram em Benguela, apenas seis (6) realizaram o retorno ao Brasil.

Em razão da prevalência do comércio de escravizados que obtinha do Brasil o fornecimento de importante parcela de gêneros coloniais quase não se observa produção local que, por sua vez, influenciava no baixo quantitativo de embarcações oriundas de outras possessões portuguesas para a realização comercial. Essa observação não só demonstra a ineficácia do Alvará de 6 de dezembro de 1824 em promover uma maior troca de todo o Reino com Angola, como ajuda a confirmar a hipótese de favorecimento da circulação da produção do Brasil com o controle de parte do circuito interno angolano.

O domínio dos negociantes brasileiros terminava por fornecer o necessitado e a promover uma maior movimentação comercial e a gerar vultosos rendimentos para Angola. Dos direitos de entrada sobre os subsídios dos molhados em Benguela foram recolhidos o total de 1:434\$350 réis ${ }^{29}$ que proporcionou a circulação de 46 produtos. Já o escravizado, principal "mercadoria", provocou o recolhimento sobre o direito de saída a receita de 39:546\$000 réis. ${ }^{30}$

Destinado em sua imensa maior parte ao Rio de Janeiro, o escravo era naquele momento absorvido, em sua maioria, pela lavoura cafeeira que apresentava forte e crescente expansão já refletindo no mercado 
com a exportação de 224.000 sacas.[1] Com a crescente presença do café do Brasil no mercado, surgem as primeiras reclamações de comerciantes frente ao favorecimento da produção brasileira que segundo os reclamantes provocavam a desvantagem e o atraso do que poderia ser produzido nas possessões. Mediante ao favorecimento da entrada do café brasileiro em Lisboa foi entregue a Real Junta do Comércio em 19 de junho de 1826, uma Representação dos Comerciantes da Praça de Lisboa, na qual solicitava providências acerca do estado em que se encontravam as Ilhas de Cabo Verde. O documento continha 22 assinaturas e pontuava sete motivos que, segundo os assinantes, mantinha Cabo Verde improdutivo.

Motivada pelo beneficiamento oferecido à produção brasileira por meio do art. $10^{\circ}$ do Tratado de Paz e Aliança de 29 de agosto de 1825, a representação detinha como argumentação central a possibilidade de passar a fornecer os produtos que o Brasil enviava a "May pátria" por meio da proposta de transformar Cabo Verde em fornecedor dos mesmos artigos coloniais a argumentar como fator positivo para a mudança seu decadente estado.

Ressaltamos essa passagem do documento que apesar do estado decadente das ilhas, as mesmas eram apresentadas como "susceptíveis de produzirem em grande quantidade todos os gêneros de entidade brazilica". ${ }^{32}$ E em razão dessa "qualidade" era solicitado a isenção do pagamento dos direitos por determinado período até alcançar uma constante e maior produção, pagamento de $10 \%$ ad valorem para a exportação ou mantimento de navios e a redução dos $30 \%$ de direito de importação e consumo, mais a equiparação e favorecimento do ingresso da produção de Cabo Verde nos mercados de Portugal.

Com relação à manutenção das taxas diferenciadas para os produtos brasileiros após a sua emancipação, o que a motivava? Dependência da produção?

Apontado como principal razão pela improdutividade das Ilhas, a cobrança sobre a produção cabo-verdiana era considerada incoerente pelos comerciantes que exemplificavam o "absurdo": "que huma arroba de Caffe de Cabo Verde para muito perto de $1 \$ 800$ reis e a mesma arroba de Caffe brazileiro sobe mui pouco de 600 reis, sem que o consumidor de maior valor aquelle do que a este. Que taes são os males que afligem e conservão improdutivas as Ilhas de Cabo Verde". 33

A partir dessa informação constante da Representação dos Comerciantes tomam os conhecimento não só do valor da comercialização como da existência da produção de café pela possessão, a demonstrar que as propostas de desenvolver os domínios portugueses ainda nas Cortes Extraordinárias podem ter contribuído na expansão da cultura cafeeira.

Para apurar a solicitação dos requerentes, foi ordenado a Antonio Pussich ${ }^{34}$ que atuasse como informante e emitisse parecer sobre o pretendido e argumentado na Representação. Salientou a riqueza fértil do solo das Ilhas e a produção, possível, de todos os "fructos do Brazil" a destacar "que alguns destes fructos como o caffé, anil e água ardente de cana de assúcar são de melhor qualidade dos de Brazil". ${ }^{35}$

Para animar o comércio de Cabo Verde, segundo Antonio Pussich era necessário que todos os gêneros e produtos exportados para Portugal pagassem na alfândega os mesmos direitos ou menor que pagavam os do Brasil; "liberdade de direitos para o comércio interno entre as Ilhas; as terras incultas e as que se abrirem livres de foro por 10 anos e a liberdade de direitos para os produtos portugueses destinados a Cabo Verde. ${ }^{36}$

Ainda de acordo com Pussich a Ilha de São Vicente era "quazi todo baldio, a qual pela vastidão e segurança do seo porto em todas as estações do anno e pela preciozidade do seu terreno virgem, apto para todas as produções". Afora a riqueza do solo, o segundo motivo para a transformação era a "sua primitiva decadência e mizeria". ${ }^{37} \mathrm{Ou}$ seja, uma imensa quantidade de terras virgens que possibilitavam o cultivo do café, apesar de já ter sido considerada nociva por ser muito "ventosa".

Tudo indica que a Representação dos Comerciantes encontrou apoio ou teve um porta-voz na Câmara dos Deputados. O deputado Jerónimo do Barco da Soledade $^{38}$, denominado na documentação como Bispo de Cabo Verde, apresentou em 10 de fevereiro de $1827^{39}$ uma proposta em que argumentava em defesa das Ilhas de Cabo Verde, apontadas na Europa como locais de morte daqueles que para lá se dirigiam. Segundo o legislador, o próprio era um exemplo vivo da mentira daquela afirmação espalhada pelos escritores. Lá vivendo há mais de seis anos, afirmou que qualquer europeu que buscasse se estabelecer nas Ilhas deveria levar consigo qualidades moral e não se entregar a bebidas e prostitutas.

Ao relatar sobre a vida que levava em Cabo Verde, informou que gastou mais de quatro anos visitando o bispado e que pôde pisar em todos os terrenos e observar os produtos que eram produzidos e os poderiam ser a ressaltar a existência de "terrenos incultos, que nunca virão ferro do lavrador, tão virgens como Adão os deixou" e "(...) capazes de produzir todos os gêneros dos trópicos do Brazil, e em grande parte as especiarias da Ázia".

A argumentação do deputado apresentava muitos pontos em comum com a Representação dos Comerciantes de 1826: por exemplo: a citação do plantio do "café, o arroz, o tabaco, a canafístola, o sene, o tamarino, o anil e o algodão" 40 apontados como os mais lucrativos e vantajosos.

A proposição do deputado Jerónimo do Barco buscou claramente apresentar a riqueza do solo e sua grande oferta a possibilitar o desenvolvimento 
da agricultura que passaria pela criação do cargo de Inspector para cuidar da lavoura e manufaturas com a função e liberdade de "mandar vir de fora do paiz as plantas e sementes que nelle não há". Essa proposta desdobraria na formação de uma Junta Promotora da Agricultura e Indústria e assim promoveria o cultivo do "solo rico que sem motivo aparente fora desprezado e/ ou abandonado".

Considerando o relatório das culturas agrícolas de 1818, Representação dos Comerciantes e a proposta apresentada à Câmara dos deputados que citaram a cultura agrícola de Cabo Verde, ficou evidente o desconhecimento daquilo que era comercializado na possessão. A ignorância explica-se pela própria geografia do arquipélago que possibilitava a utilização de diversos pontos pelo comércio que terminava por dificultar o pleno conhecimento do que era barganhado. A comprovação do fato é encontrada na comunicação do governador João da Mata Chapuzet a informar que “(...) alfầndegas não estavão proporcionadas a fertilidade das ilhas, á extenção actual do seu comércio e quantidade das riquezas importadas para consumo". ${ }^{41}$

\section{O desconhecimento daquilo que era comercializado nas possessões e a busca por arrecadação}

$\mathrm{Na}$ busca pelo conhecimento daquilo que era comercializado apresentamos o registro da importação e exportação do porto da Ilha de São Nicolau do período de dezembro de 1825 a maio de 1826 que anotou 32 embarcações, cujos portos de origem ${ }^{42}$ eram pertencentes a Cabo Verde, exceto um da cidade do Porto e dois de Londres, a demonstrar a existência do circuito comercial bastante interessante com o embarque de panos, couros, urzela e tabaco. ${ }^{43}$ Por sua vez, as descargas ou "cargas que trás" foram de: sal; várias fazendas; resto de cargas, urzela, resto de fazenda; arroz: vários gêneros e milho.

Já no mapa sobre "aportação e exportação" 44 da mesma Ilha para todo o ano de 1826, as informações revelam uma maior variedade de produtos com a presença do café, sem especificar a quantidade, apenas informando a soma total de cada navio. Quanto à carga "aportada" dos 16 registros, apenas 2 apresentaram produtos distintos dos citados acima, farinha e tijolo. Já a exportação foi de "peles, couros, café, égua, tabaco, urzela, panos e efeitos". ${ }^{45}$

Os mapas de registros de importação e exportação não se limitaram à Ilha de São Nicolao. Santo Antão apresentou dois embarques de café. O primeiro registro foi acompanhado da observação sobre a pouca quantidade destinada a Ilha da Madeira. ${ }^{46}$ Já o segundo, apenas informou o embarque. A Ilha da Boa Vista não apresentou despacho de café. ${ }^{47}$

Preocupado com a situação da possessão, o governador confeccionou um regimento ${ }^{48}$ com o objetivo de entender melhor o comércio local e sua extensão com o intuito de obter maior rendimento. No documento sugeriu a necessidade de um novo regulamento das alfândegas, que até aquele momento eram reguladas por "disposições particulares dos Foraes das Ilhas", ${ }^{49}$ que ocasionava o descaminho da arrecadação. Uma segunda observação abordou o número insuficiente de empregados e de estações fiscais e a consequente necessidade de aumento do quantitativo de funcionários.

A justificativa para a criação do regimento era diminuir os desvios comerciais e aumentar a fiscalização como meio de alavancar a arrecadação. Segundo João da Matta, a existência de práticas comerciais sem fiscalização "não só he visilmente permiciozo aos interesses da Real Fazenda, mas tem paralizado quaes quer esforços na extensão de elevar a civilização e commercio da cappital a hum terreno de proporção com sua fertilidade natural". ${ }^{50}$

Enquanto em Cabo Verde buscava ter o conhecimento e controle sobre o que era comercializado com o objetivo de gerar uma maior arrecadação, em São Tomé e Príncipe o panorama era de pagamento de dívidas e queda da arrecadação.

Buscando a solução para a queda da arrecadação, o governador de São Tomé e Príncipe, Jose Maria Xavier Brito, consultou o ministro e secretário de Estado dos Negócios Estrangeiros ${ }^{51}$ sobre as apreensões realizadas pelos cruzadores ingleses na possessão. Por sua vez, o ministro remeteu a explicação obtida do embaixador da Inglaterra que as intervenções se encontram em conformidade com o estabelecido anteriormente. $\mathrm{O}$ ministro português entendia que a entrada de escravizados era permitida, desde que (...) nos Portos em que pelos Tratados nos he permittido fazer escravos" e solicitava "a necessidade que há de remover obstaculos tão funestos á propriedade das poucas colônias Portuguezas que ainda restão". ${ }^{52}$

Em 5 de janeiro de 1826 foi encaminhada resposta a comunicação. $\mathrm{O}$ ofício informava sobre a autorização real concedida ao embaixador português em Londres para realizar as necessárias reclamações junto ao governo inglês quanto às ações de seus cruzadores.

Com a arrecadação em queda, procuravam-se saídas que pudessem provocar o seu aumento, sendo o tráfico uma opção. E parece que o pedido do governador provocou pequena reação na receita da Ilha do Príncipe. Se em 1825 os direitos sobre a importação de escravos atingiram $2,05 \%{ }^{53}$ do total da receita, no ano seguinte a porcentagem atingiu $10,10 \%{ }^{54}$.

Já em relação à exportação do café o oposto ocorreu. Se em 1825 a comercialização proporcionou a Ilha de Príncipe ${ }^{55}$ a arrecadação de 1:420\$067 réis, no ano seguinte o quantitativo foi de apenas 557\$931 réis.

Entretanto, em ofício encaminhado pelo 
governador com data de 21 de janeiro de 1826 encontrase a observação do próprio sobre a "melhora" das rendas públicas que "tem augmentado algum tanto por efeito de zelosa arrecadação". Continuava o governador: "na Ilha de Príncipe pagarão-se durante o sobredito ano de 1825 todos os dívidas atrazadas", já na Ilha de São Tomé "os pagamentos dos Filhos de Folha achão-se em dia, pagarão-se no ano passado muitas dívidas atrazadas". ${ }^{56}$

De acordo com as informações repassadas tem-se a interpretação que a possessão de São Tomé e Príncipe encontrava-se em momento de recuperação econômica com a quitação de suas dívidas. Entretanto, quando analisa os dados contidos nos quatro mapas de receita e despesa é possível obter relevantes informações. No mapa da receita da Ilha do Príncipe nos rendimentos da Repartição da Alfândega encontra-se a informação sobre o dízimo do café exportado em navios nacionais e estrangeiros. O documento informa que na Ilha do Príncipe no ano de 1825 o café proporcionou a receita de 1:420\$067 réis. O mesmo se observa em São Tomé, que apresentou uma receita de $392 \$ 934$ réis sobre o mesmo direito. A soma da arrecadação sobre o café apresentou o valor de 1:813\$001 de uma receita total de 22:389\$174 réis. ${ }^{57} \mathrm{Ou}$ seja, $8,09 \%$ do total.

Contudo, quando se compara a arrecadação de 1825 com a de 1824 fica evidente a perda de receita, mesmo com o governador chamando a atenção em seu ofício para a zelosa administração, que, segundo $\mathrm{o}$ próprio, trouxe aumento da arrecadação. $\mathrm{Se} \mathrm{em}$ 1824 o total arrecadado foi de 24:658\$489 réis, em 1825 arrecadou apenas 22:389\$174 réis. $^{58}$ Logo, a argumentação de aumento da arrecadação é uma inverdade quando se realiza o somatório global.

É verdade que houve aumento da arrecadação na Ilha do Príncipe, 2:007\$884 réis a mais em relação a 1824, como é verdade que houve queda em São Tomé de 4:276\$929 réis. Esse foi o motivo da contradição da argumentação do Governador de São Tomé e Príncipe.

A existência de desequilíbrio na arrecadação das Ilhas era evidente, tão evidente que o mesmo era camuflado pela retórica do ofício. Também é verdade que o governador vinha realizando o pagamento de antigas dívidas. Só no ano de 1825 ele quitou o montante de 6:634\$559 referentes aos "empregados da folha civil, militar e eclesiástica e a particulares contraídas por urgência" ${ }^{59}$. Contudo, as Ilhas deviam ao Cofre Real

Tabela 6. Receita e despesa de São Tomé e Príncipe.

1825

\begin{tabular}{cr}
\hline Receita & $22: 389 \$ 174$ \\
\hline Despesa & $26: 580 \$ 473$ \\
\hline $\begin{array}{c}\text { Receita a favor do } \\
\text { Cofre Real }\end{array}$ & $778 \$ 014$ \\
\hline Deve ao Cofre Real & $8: 383 \$ 879 *$ \\
\hline
\end{tabular}

8:383879 réis, após gerar uma receita a favor do mesmo Cofre de $778 \$ 014$ réis. seguinte:

Simplificando essas informações, temos o

A tentativa de esconder a situação pela qual se encontrava a possessão ficou desnuda quando em 21 de janeiro de 1826 o governador informou a impossibilidade do envio de cavalos para Angola em razão da extinção das boas raças e: "desde que decahio esta colônia, e se tornou de mui rica, opulenta, e muito povoada a pobre, mizeravel, e quazi deserta, pela emigração dos seos principais habitantes para o Brazil (...) buscar melhor clima e mais vantagens que lhes ofereção o Commercio e a Agricultura" 61.

O que estaria possibilitando a São Tomé e Príncipe iniciar a quitação de parte da dívida existente num contexto de emigração de seus habitantes e de queda da arrecadação?

Buscando o entendimento, isolamos as Ilhas. A do Príncipe apresentou no ano de 1825 a despesa de $14.550 \$ 019$, isto é, $1.294 \$ 891$ réis maior que a despesa do ano de 1824. Com o pagamento de dívidas em atraso totalizando $4.225 \$ 501^{62}$ encontramos um dos motivos pelo aumento. A receita, por sua vez, apresentou o total de $15.000 \$ 520$ réis resultando num superávit de $450 \$ 501 .{ }^{63}$ Ao comparar com a receita do ano de 1824 , verifica-se o acréscimo de $2.007 \$ 884$. Seria a produção de café na Ilha do Príncipe um dos responsáveis pelo aumento da arrecadação?

Por sua vez, a Ilha de São Tomé em 1825 apresentou uma receita de $7.388 \$ 654,{ }^{64}$ inferior em $36,67 \%$ a alcançada no ano anterior. Já a despesa foi de 12:030\$454, superior em 3:888\$830 ao do ano anterior. Especificamente em São Tomé se subtrairmos o valor referente ao pagamento das dívidas em atraso, a despesa continua superior a receita com o quantitativo de 9:351\$760 a gerar o déficit de 1:963\$106 réis.

Em relação ao recolhimento sobre a exportação do café, encontramos a arrecadação em Príncipe de 1:420\$067 e em São Tomé de 392\$934 réis. Valores que possibilitaram, especificamente na Ilha de Príncipe o saldo positivo. Sobre esse produto em ascensão, localizamos um comunicado que abordava a qualidade e quantidade do grão exportado relatando que "O café das Ilhas de S. Thomé e Principe he tão bom como o de Moka, e não obstante a sua plantação não se achar tão adiantada como pode ter, só na Ilha de Príncipe passa de cem mil arrobas a exportação annual deste precioso artigo do com ${ }^{0} .{ }^{65} \mathrm{O}$ cultivo do café era uma cultura em plena expansão e apontado como o principal produto a alavancar o desenvolvimento das Ilhas, o que gerou o relato do governador:

Hoje porém He nestas Ilhas hum gênero de exportação preciozíssimo pela sua qualidade e quantidade, que he o Caffé, procurado anciozamente por todas as Nações 
(exceto a Portugueza) que aqui o vem comprar. As plantações tem incrivelmente augmentado todos os anos: He o único trabalho a que se dão hoje os habitantes destas Ilhas, ricos e pobres. A exportação do Caffé He infalível: consome-se muito pouco no Paiz, mas nem hum só grão fica por vender de uma colheita para outra.Requeiro por tanto que os dízimos do Caffé sejão arrematados por Contracto, e que se paguem não só os dízimos do Caffé que se exportão mas sim de todo o Caffé que se colher, como He pratica geral em toda a parte respectivamente a este antigo dízimo; embora nestas Ilhas em benefício da cultura fiquem todos os maiz gêneros continuando a pagar dízimos somente do que se exportar e no do que se colher ${ }^{66}$.

Quanto a não procura por Portugal pelo café da possessão há de ter em consideração o abastecimento realizado pelo Brasil com taxação inferior ao da possessão. Dessa maneira, tudo indica que Portugal optava por desenvolver e expandir em seus domínios o cultivo da rubiácea.

\section{A afirmação do café e a ausência de benefícios alfandegários}

Já no início da segunda metade da década de 1820 , o café se apresentava para Portugal como aposta segura, tendo a seu favor o desempenho produtivo nas possessões e, principalmente, a procura do mercado externo pelo grão.

Após o último debate sobre o cultivo do café para promover o desenvolvimento agrícola dos domínios de Portugal em África pela Câmara dos deputados em 1823, a rubiácea ressurge em 1826 nos debates inseridos na proposta de lei que buscava promover o cultivo de diversos gêneros coloniais.

Diferentemente do ocorrido nas Cortes Extraordinárias com a iminente emancipação do Brasil, a nova propositura que re-apresentou o café ocorreu já após o reconhecimento português da independência, com a manutenção de taxas preferenciais para a produção brasileira.

Em 11 de dezembro de 1826, o deputado José Antonio Ferreira Braklami ${ }^{67}$ propôs o projeto de lei que buscava "promover, e adiantar quando suas forças, e faculdades permittem, a População, Agricultura, Commercio, e Industria, e Navegaçao" das possessões em África. Propunha isentar e cortar pela metade as taxas e direitos de importação na metrópole. De acordo com a proposta, o objetivo dos cortes era incentivar a produção e o povoamento e a colonização das possessões, que em função do predomínio do Brasil ficaram em segundo plano e, na maioria das vezes, desempenharam a função de fornecedora de mão de obra escrava que produzia e explorava a riqueza da ex-colônia.

Segundo o deputado, enquanto o Brasil pertenceu ao Reino houve negligência para com os demais domínios. E por esse motivo propunha implantar e/ou incentivar a produção de gêneros coloniais como forma de atenção e preocupação para com as possessões. Fundamentado no novo cuidado, destacamos o art. $2^{\circ}$ do projeto de lei que isentava de taxação não só os que já eram produzidos, mas o "que se possão exthrair (...) e para o futuro".

Todavia, a proposta não se limitou apenas a implantação da diversidade agrícola. Existia outra preocupação talvez despertada após o desinteresse da Inglaterra pelo vinho da Madeira alguns anos antes. O art. $3^{\circ}$ buscava a abertura de mercado para o consumo de vinho produzido e, por conseguinte, impedir o consumo da aguardente no mercado africano, assim como os panos produzidos nas possessões. Para alcance desse objetivo, tanto o vinho quanto os "panos portugueses de lá" ficariam absolutamente livre de direitos de exportação e importação.

Demonstrada a preocupação em diminuir o alcance da produção externa nos mercados africanos, surge a face protecionista da proposta do deputado Braklami que buscava a criação de um mercado lusoafricano com o claro objetivo de limitar a interferência comercial externa e, dessa maneira, repor o que antes era oferecido pelo Brasil.

Outro ponto abordado pelo projeto foi à utilização de embarcações no comércio entre a metrópole e as possessões, com o objetivo de priorizar, com taxas preferenciais, navios portugueses. $\mathrm{Na}$ impossibilidade, a utilização de embarcações estrangeiras ficariam sujeitas ao pagamento dos antigos direitos além de um adicional de 3\% ad valorem a ser aplicado em construções de infraestrutura tidas como indispensáveis para a realização do comércio e navegação entre os continentes. Uma clara tentativa de fugir do domínio inglês existente sobre o frete marítimo.

Tratava-se, portanto, de um projeto que de uma só vez objetivava monopolizar todos os possíveis ramos comerciais que envolviam a barganha entre Portugal e suas possessões em África, que ainda propunha a distribuição de terras "vagas" portugueses, tanto individualmente ou coletivamente ${ }^{69}$. Nas obrigações dos agraciados com o recebimento da terra obtemos o conhecimento daquilo que procurou desenvolver: "levanta[r]em engenho de assucar, ou para roçados, em que se plante e semeie o Arroz, Café, Algodão, Cacao, Tabaco e Cereaes". ${ }^{70}$

Essa proposta de doação era justificada pela situação econômica de Portugal após o reconhecimento da independência do Brasil, que segundo os deputados não era favorável.

Dias antes da propositura de Braklami, em 30 de novembro de 1826 o deputado barão de Quintela salientou a necessidade de melhoramentos para sair da situação de decadência após anos de “(...) immensos thesouros: Um commercio de monopolio, seguido das ricas produções do Brasil" ${ }^{\prime 71} \mathrm{e}$ sugeriu a liberdade 
ao cidadão português ou a associados de empreender a própria custa obras de infraestrutura com a única finalidade de dar vida ao Estado e aumentar a circulação de riquezas, a qual beneficiava todo o país.

Mediante o horizonte que despontava com as proposituras dos deputados, algumas margens do Reino começaram a buscar soluções para promover e estimular suas produções ou comércio. Em uma dessas buscas, constatou-se, uma vez mais, em dezembro de 1826 com a estagnação do comércio do vinho da Ilha da Madeira que se mantinha como o único gênero de exportação. Confirmada a estagnação por mais de três ciclos anuais, o deputado Pimenta de Aguiar propôs a liberdade de transporte dos vinhos madeirense, assim como a autorização de importar produções naturais dos destinos finais dos vinhos. Mais uma vez o objetivo era estimular a "definhada Agricultura" 72 .

A proposta de Pimenta guardava similaridade com a do deputado Braklami que propunha a isenção do pagamento de direitos ou impostos para os produtos que tivessem como ponto de origem a África Oriental e a isenção da metade dos impostos cobrados para os da África Ocidental. Naquele momento, a principal motivação para os pedidos de redução das taxas era a existência de direitos distintos sobre os produtos brasileiros em detrimento da produção oriundas dos domínios portugueses.

Tendo em consideração as propostas apresentadas e debatidas na Câmara dos deputados, a publicação do Alvará de 6 de dezembro de 1824 e a Representação dos Comerciantes da praça de Lisboa; ponderamos sobre a ausência de benefícios alfandegários que pudessem impulsionar a comercialização dos grãos produzidos pelas possessões que até aquele momento sofria com as alíquotas favoráveis à produção do Brasil.

Podemos concluir que a dependência portuguesa da produção brasileira, evidenciada no Tratado de Paz e Amizade, prejudicou naquele momento, mesmo com os projetos e a implantação de uma maior diversidade de culturas agrícolas nos domínios em África, um maior desenvolvimento e avolumamento da agricultura nesses mesmos domínios a impactar diretamente na implantação e/ou expansão da cultura cafeeira.

\section{Abreviaturas}

AHU- Arquivo Histórico Ultramarino.

BNL- Biblioteca Nacional de Lisboa.

CU- Conselho Ultramarino.

PT- Portugal.

\section{Fontes}

Arquivo Histórico Ultramarino (Avulsos).

Angola:

PT/AHU/CU - Angola, Cx 153, doc 29.
PT/AHU/CU - Angola, Cx 159, doc 13.

PT/AHU/CU - Angola, Cx 150, doc 25.

Cabo Verde

PT/AHU/CU - Cabo Verde, Cx 81, doc 21. PT/AHU/CU - Cabo Verde, Cx 85, doc 35. PT/AHU/CU - Cabo Verde, Cx 86, doc 52. PT/AHU/CU - Cabo Verde, Cx 85, doc 35. PT/AHU/CU - Cabo Verde, Cx $85^{\mathrm{a}}$, doc 81 .

São Tomé e Príncipe:

PT/AHU/CU - São Tomé e Príncipe, Cx 56, doc 71. $\mathrm{PT} / \mathrm{AHU} / \mathrm{CU}$ - São Tomé e Príncipe, Cx 55, doc 14. PT /AHU/CU - São Tomé e Príncipe, Cx 56, doc 72. PT/AHU/CU - São Tomé e Príncipe, Cx 56, doc 66. PT/AHU/CU - São Tomé e Príncipe, Cx 55, doc 38. PT/AHU/CU - São Tomé e Príncipe, CX, 57, doc 08. PT/AHU/CU - São Tomé e Príncipe, Cx 57, doc 29.

Debates Parlamentares - Disponível em: http://debates.parlamento.pt Debates Parlamentares das Cortes Gerais Extraordinárias da Nação Portuguesa 1821-1822. Lisboa, 07 de julho de 1821.

Debates Parlamentares das Cortes Gerais Extraordinárias da Nação Portuguesa 1821-1822. Lisboa, 15 de março de 1822.

Debates Parlamentares das Cortes Gerais da Nação Portuguesa 1827. Lisboa, 13 de fevereiro de 1827 .

Proposição apresentada em 10 de fevereiro de 1827. In: Debates Parlamentares da Câmara dos Senhores deputados da Nação Portuguesa 1822-1910, p. 294.

Debates Parlamentares das Cortes Gerais da Nação Portuguesa 1827. Lisboa, de 12 de fevereiro de 1827. Disponível em: http://debates.parlamento.pt.

Debates Parlamentares das Cortes Gerais Extraordinárias da Nação Portuguesa 1821-1822. Lisboa, de 08 de junho de 1822.

Debates Parlamentares da Câmara dos Senhores deputados da Nação Portuguesa 1822-1910. Lisboa, fevereiro de 1823, p. 805.

Debates Parlamentares da Câmara dos Senhores deputados da Nação Portuguesa 1822-1910. Lisboa, 11 de dezembro de 1826, p. 159.

Proposição apresentada em 30 de novembro de 1826. In: Debates Parlamentares da Câmara dos Senhores deputados da Nação Portuguesa 1822-1910. Lisboa, 11 de dezembro de 1826, p. 161.

Requerimento apresentado em 13 de fevereiro de 1827. In: Debates Parlamentares da Câmara dos Senhores deputados da Nação Portuguesa 1822-1910, p. 316.

Legislação Régia - Disponível em: http://legislacaoregia.parlamento.pt

Alvará de 25 de abril de 1818 .

Alvará de 6 de dezembro de 1824

\section{Notas}

1. Discente do Programa Interuniversitário de Doutoramento em História (PIUDHist). Instituto de Ciências Sociais (ICS) e Centro de História da Faculdade de Letras - Universidade de Lisboa. Bolsista Capes.

2. Alvará de 25 de abril de 1818. Disponível em: http://legislacaoregia. parlamento.pt. Acesso em: 10 de fevereiro de 2017.

3. FLORENTINO. Manolo G. Nota sobre os negócios negreiros no porto do Rio de Janeiro. Apud.. FRAGOSO, João Luis. Homens de grossa aventura acumulação e hierarquia na praça mercantil do Rio de Janeiro 1790-1830. 2 ed. Rio de Janeiro: Civilização Brasileira, 1998, p, 145.

4. MARQUESE, Rafael e TOMICH, Dale. O Vale do Paraíba escravista e a formação do mercado mundial do café no século XIX. In: GRINBERG, Keila e SALLES, Ricardo. O Brasil Imperial, volume II: 1831-1840. Rio de Janeiro: Civilização Brasileira, 2009, p, 355. BNL. PORTO-ALEGRE, Paulo. Monographia do café, história, cultura e producção. Lisboa : [s.n.], 
1879, p, 473. TAUNAY, Affonso d'Escragnolle. Pequena História do Café no Brasil: 1727-1937. Rio de Janeiro: Departamento Nacional do Café, 1945, p, 50.

*Os dados apresentados por Marquese e Tomich referem-se à exportação do Brasil.

** Os dados apresentados por Porto Alegre também é relativo à exportação do Brasil.

*** Os dados apresentados pela Associação Comercial do Rio diz respeito apenas a exportação do Rio de Janeiro.

5. Debates Parlamentares das Cortes Gerais Extraordinárias da Nação Portuguesa 1821-1822. Lisboa, 07 de julho de 1821. Disponível em: http:// debates.parlamento.pt

6. O Erário recolheu 65 sacas de café e 193 caixas de anil sob a alegação de se tratar de produtos pertencentes aos franceses. Contudo, Anna Mallet aparece "com uris, embargos de terceira senhora e possuidora, allegando serem aquelles effeitos seus, e não pertencentes aos Fiancezes, e tratando-se destes embargos no juizo da Coroa e Fazenda". Assim, " apezar da falta de prova, furão aquelles embargos recebidos, e julgados provados., com offensa a mais notoria, e até escandalosa da Fazenda Nacional, ficando assim privada tão injustamente de mais de quarenta e quatro contos de réis".

7. Debates Parlamentares das Cortes Gerais Extraordinárias da Nação Portuguesa 1821-1822. Lisboa, 15 de março de 1822. Disponível em: http:// debates.parlamento.pt

8. Entendam-se ambas as margens como sendo Portugal e Brasil.

9. Debates Parlamentares das Cortes Gerais Extraordinárias da Nação Portuguesa 1821-1822. Lisboa, 15 de março de 1822. Disponível em: http:// debates.parlamento.pt.

10. Debates Parlamentares das Cortes Gerais Extraordinárias da Nação Portuguesa 1821-1822. Lisboa, 08 de julho de 1822. Disponível em: http:// debates.parlamento.pt

11. Solicitação de 25 de outubro de 1824 , inicialmente realizada "nas ilhas e terras de Guiné" e, posteriormente na Ilha de São Tiago de Cabo Verde. PT/ AHU/CU - Cabo Verde, Cx 79, doc79.

12. Sal nativo e artificial, urzela, anil, algodão, milho, erva do tabaco, vinho, feijão, abóbora, mandioca, cana de açúcar, açúcar, aguardente, melaço, banana, laranja, ananás, melancia, hortaliça. A Urzela era comercializada, mas era monopólio da Coroa. Ibidem.

13. Debates Parlamentares da Câmara dos Senhores deputados da Nação Portuguesa 1822-1910. Lisboa, fevereiro de 1823, p. 805. Disponível em: http://debates.parlamento.pt.

\section{PT /AHU/CU - São Tomé e Príncipe, Cx 55, doc25.}

15. A Administração de São Tomé e Príncipe recebia até o ano de 1824 o pagamento anual no valor de 9 contos de réis realizado pela Alfândega da Bahia a título de direitos sobre os escravos exportados. NASCIMENTO, Augusto. São Tomé e Príncipe. In:VALENTIM, Alexandre e DIAS, Jill. Nova História da expansão portuguesa (volume X): o império africano (1825-1890). Lisboa: Editorial Estampa Lda, 1998, p, 272.

16. A cultura do café foi introduzida na Ilha de São Tomé em 1789 pelo capitão-mor João Baptista da Silva que trouxe sementes e/ou mudas do Brasil. E já no início na primeira década do século XIX se tornou numa das principais culturas da possessão. In: FERRÃO, José E. Mendes. $O$ Café: a Bebida negra dos sonhos claros. Lisboa: Chaves Ferreira Publicações, AS , 2009, p, 31 .

17. PT/AHU/CU - São Tomé e Príncipe, Cx 57, doc 29.

18. Idem.

19. PT/AHU/CU - São Tomé e Príncipe, Cx 55, doc 38.

20. PT/AHU/CU - Angola, Cx 159, doc13. AHU.

21. Idem.

22. Dados extraídos da comunicação do governador de Angola. AHU. Conselho Ultramarino, Angola, Maio de 1828. Caixa 159, Documento 13.

* BNL. PORTO-ALEGRE, Paulo. Monographia do café, história, cultura e producção. Lisboa : [s.n.], 1879, p, 473.

** TAUNAY, Affonso d'Escragnolle. Pequena História do Café no Brasil: 1727-1937. Rio de Janeiro: Departamento Nacional do Café, 1945, p, 547.
23. Alvará de seis de dezembro de 1824. Disponível em: http://legislacaoregia. parlamento.pt. Acesso em 09 de fevereiro de 2017.

24. GUIZELIN, Gilberto da Silva. Depois dos navios negreiros: a criação do Consulado Brasileiro em Luanda e as relações do Império com a colônia portuguesa de Angola, 1822-1860. Tese apresentada ao Programa de PósGraduação em História da Universidade Estadual Paulista Júlio de Mesquita Filho. Franca 2016, p, 116.

25. PT/AHU/CU - Angola, Cx 150, doc 25.

26. Idem.

27. PT/AHU/CU - Angola, Cx 153, doc 29.

*Não cultivadas.

28. PT/AHU/CU - Angola, Cx 153, doc 29

*Exeques

** Total a considerar tijolos grandes e pequenos.

29. PT/AHU/CU - Angola, Cx 153, doc 29.

30 Idem.

31. TAUNAY, Affonso d'Escragnolle. Pequena História do Café no Brasil: 1727-1937. Rio de Janeiro: Departamento Nacional do Café, 1945, p, 547. Há uma outra informação que apresenta o quantitativo de 101.410 sacas In: BNL. PORTO-ALEGRE, Paulo. Monographia do café, história, cultura e producção. Lisboa : [s.n.], 1879, p, 473.

32. PT/AHU/CU - Cabo Verde, cx 85A, doc 81.

33. PT/AHU/CU - Cabo Verde, cx 85A, doc 81.

34. Ex-governador de Cabo Verde (1818-22).

35. PT/AHU/CU - Cabo Verde, cx 85A, doc 81,

36. Idem.

37. Idem.

38. nformação retirada do Dicionário do Vintismo e do primeiro Cartismo (1821-1823 e 1826-1828) Volume II.

39. Proposição apresentada em 10 de fevereiro de 1827. In: Debates Parlamentares da Câmara dos Senhores deputados da Nação Portuguesa 1822-1910, p. 294. Disponível em: http://debates.parlamento.pt

40. Idem.

\section{PT/AHU/CU - Cabo Verde, Cx 81, doc 21.}

42. Portos: Boa Vista; Ilha de Maio; São Antão; Santiago; Ilha Brava; São Vicente; Cabo Verde; Ilha do Fogo, Cidade do Porto, vila da Praia e Terraffal de Cabo Verde. PT/AHU/CU - Cabo Verde, Cx85, doc35.

43. PT/AHU/CU - Cabo Verde, Cx 86, doc 52.

44. O mapa apresenta a coluna "que fazenda exportarão" duplicada. Como em seu título o documento informa "gêneros que Aportarão e Exportarão", consideramos a primeira coluna de gêneros "aportados" e a segunda de exportados.

45. PT/AHU/CU - Cabo Verde, Cx 85, doc 35.

46. PT/AHU/CU - Cabo Verde, Cx 85, doc 35.

47. Os produtos embarcados nas duas Ilhas, além do café foram: urzela, peles, couros, panos, sal e aguardente. Em nenhuma outra ilha, exceto as citadas, houve embarque de café.

48. PT/AHU/CU - Cabo Verde, Cx 81, doc 21. Nome dado ao documento pelo próprio Governador.

49. Idem.

50. Idem.

51. Antonio de Saldanha da Gama, Conde de Porto Santo 
52. PT/AHU/CU - São Tomé e Príncipe, Cx 56, doc 66.

53. A receita do ano de 1825 foi de 15:000\$520 réis com a arrecadação de $308 \$ 000$ réis sobre os direitos de importação de escravizados.. PT/AHU/ CU - São Tomé e Príncipe, Cx 56, doc 72.

54. Já a receita de 1826 foi de 7:789\$902 réis com a arrecadação de $787 \$ 500$ réis sobre os direitos de importação de escravizados. PT/AHU/CU - São Tomé e Príncipe, Cx 57, doc 08.

55. Os dados são referentes apenas a Ilha do Príncipe em razão da pesquisa não ter encontrado mapas da receita e despesa da Ilha de São Tomé para o ano de 1826 .

56. PT/AHU/CU - São Tomé e Príncipe, Cx56, doc. 72.

57. Idem.

58. Idem.

59. PT/AHU/CU - São Tomé e Príncipe, Cx56, doc72.

60. Idem.

*Valores em réis.

61. PT/AHU/CU - São Tomé e Príncipe, Cx 56, doc 71. Grifo nosso.

62. PT /AHU/CU - São Tomé e Príncipe, Cx 56, doc 72. Valores em Réis.

63. PT/AHU/CU - São Tomé e Príncipe, Cx 56, doc 72.

64. Idem.

65. PT/AHU/CU - São Tomé e Príncipe, Cx 55, doc 14.

66. PT/AHU/CU - São Tomé e Príncipe, Cx 55, doc 38.Grifo nosso.

67. Debates Parlamentares da Câmara dos Senhores deputados da Nação Portuguesa 1822-1910. Lisboa, 11 de dezembro de 1826, p. 159. Disponível em: http://debates.parlamento.pt.

68. Terras com matas e madeira para a construção naval deveriam ser preservadas.

69. Para naturalizados somente em caso de ausência de portugueses.

70. Art. $8^{\circ}$ do Projeto.

71. Proposição apresentada em 30 de novembro de 1826. In: Debates Parlamentares da Câmara dos Senhores deputados da Nação Portuguesa 1822-1910. Lisboa, 11 de dezembro de 1826, p. 161. Disponível em: http:// debates.parlamento.pt

72. Debates Parlamentares da Câmara dos Senhores deputados da Nação Portuguesa 1822-1910. Lisboa, 11 de dezembro de 1826, p. 159. Disponível em: http://debates.parlamento.pt

Biblioteca Nacional de Lisboa.

PORTO-ALEGRE, Paulo. Monographia do café, história, cultura e producção. Lisboa : [s.n.], 1879.

TAUNAY, Affonso d'Escragnolle. Pequena História do Café no Brasil: 17271937. Departamento Nacional do Café, Rio de Janeiro, 1945.

\section{Referências}

FERRÃO, José E. Mendes. O Café: a Bebida negra dos sonhos claros. Lisboa: Chaves Ferreira Publicações, AS, 2009.

FLORENTINO. Manolo G. Nota sobre os negócios negreiros no porto do Rio de Janeiro. Apud. . FRAGOSO, João Luis. Homens de grossa aventura acumulação e hierarquia na praça mercantil do Rio de Janeiro 1790-1830. 2 ed. Rio de Janeiro: Civilização Brasileira, 1998.

FRAGOSO, Luis. Homens de Grossa Aventura - acumulação e hierarquia na praça mercantil do Rio de Janeiro 1790-1830. 2 ${ }^{\mathrm{a}}$ Ed. Rio de Janeiro:
Civilização Brasileira, 1992.

GUIZELIN, Gilberto da Silva. Depois dos navios negreiros: a criação do Consulado Brasileiro em Luanda e as relações do Império com a colônia portuguesa de Angola, 1822-1860. Tese apresentada ao Programa de PósGraduação em História da Universidade Estadual Paulista Júlio de Mesquita Filho. Franca 2016.

MARQUESE, Rafael e TOMICH, Dale. O Vale do Paraíba escravista e a formação do mercado mundial do café no século XIX. In: GRINBERG, Keila e SALLES, Ricardo. O Brasil Imperial, volume II: 1831-1840. Rio de Janeiro: Civilização Brasileira, 2009.

MARTINS, Oliveira. O Brasil e as colônias portuguesas. Lisboa: Guimarães \& Cia Editores, 1953.

NASCIMENTO, Augusto. São Tomé e Príncipe. In:VALENTIM, Alexandre e DIAS, Jill. Nova História da expansão portuguesa (volume X): o império africano (1825-1890). Lisboa: Editorial Estampa Lda, 1998.

LAHON, Didier. Eles vão, eles vêm. Escravos e libertos negros entre Lisboa e o Grão-Pará e Maranhão (séc. XVII-XIX). Revista Estudos Amazônicos. Vol. VI, n 1 (2011), pp. 70-99.

SENNA, Manuel Roiz Lucas de. Dissertação sobre as ilhas de Cabo Verde 1818. Lisboa: GáficaEuropamLda, 1987. 